\title{
LA GENERALIDAD VALENCIANA VISTA POR DIETARISTAS Y CRONISTAS
}

\author{
Rosa Muñoz Pomer \\ Universidad de Valencia
}

、 Cualquier estudio, bien sea político, institucional, social, etc., se puede, o mejor se debe, afrontar a través de las fuentes primarias y secundarias.

Las primeras por su carácter residual del propio hecho, nos permiten, utilizando el utillaje requerido al caso, un mejor conocimiento del tema en sus múltiples aspectos.

Las segundas, muy importantes ante la ausencia o merma de las primeras, tienen también su propio significado independiente de aquéllas. Señalan la repercusión o interpretación del hecho según el prisma desde el que se produjo su enfoque. Pueden servir de pauta u orientación del posterior trabajo de investigación. Proporcionan, asimismo, una primera aproximación al tema. Su cuestionabilidad no les resta importancia, han servido de punto de arranque.

Este doble planteamiento, aunque deseable, no siempre puede realizarse conjuntamente ni en toda su extensión: la abundancia de fuentes, los límites de espacio, etc.

Las excusas enunciadas son válidas ante el tema que aquí nos planteamos; la Generalidad Valenciana. Su análisis a través de ambos tipos de fuentes no es un objetivo que se pueda conseguir en los estrechos limites marcados por un artículo (1). Así pues, queremos en un primer

(1) Ambos tipos de fuentes son utilizadas, en nuestra tesis doctoral, para una mejor comprensión del papel de la Generalidad en la Edad Media. 
intento de aproximación al tema, rastrear lo que fue y significó dicha institución en el contexto económico-social-político de la Valencia en la que se desenvuelve, a través de la historiografía contemporánea.

Los dietaris, llibres de memories, cronistas, etc., son, sin duda, una fuente de información que marcará la bibliografía posterior. El primer trabajo moderno llevado a cabo sobre la institución se remonta a 1930 (2).

Dadas las características de la mencionada bibliografía la estudiaremos en dos grandes apartados - dentro de los cuales quedarán comprendidas sus distintas particularidades - Dietaristas y Cronistas.

\section{DIETARISTAS}

Según Almarche y Vázquez, autor que ha dedicado su atención a la historiografía valenciana "la mayor parte de estos escritores eran simples cronistas en la acepción moderna de esta palabra y titularon Memorias diarias, Apuntamientos cuotidianos, Quodlibetales, Noticias de sucesos que pasaban en su época o presenciaban, anotando los que estimaban más interesantes o encuadraban en su idiosincrasia especial, sin olvidad alguna vez, de formular juicio, de alabanza o de crítica" (3). El mismo señala entre sus características: la ingenuidad al relatar el hecho presenciado, el ofrecer las impresiones y prejuicios del autor, el carecer de pretensiones de estilo, el estar libre de servilismos, etc.

Entre los títulos que aporta hemos seleccionado para su análisis, los que están situados preferentemente en la Edad Media, y abarcan temática general, ya que no se encuentra ninguno específico referido a la Generalidad.

La interdependencia entre muchos de ellos se puede apreciar a simple vista. La prioridad de unos sobre otros es más difícil, la historiografía valenciana es uno de los muchos campos abandonados.

\subsection{Llibre de Memories (1308-1644)}

Según su editor, Carreres Zacares: "es ú dels mes interesants tant per el temps que conprén, 1308-1644, com per estar en gran part prés dels Manuals de Consells i haver desempenyat els seus redactors impor-

(2) MARTINEZ ALOY, J. La diputación de la Generalidad de/ reino de Valencia. Valencia 1930.

(3) ALMARCHE Y VAZQUEZ, F. Historiografia Valenciana. Catálogo bibliográfico de dietarios, libros de Memorias, diarios, relaciones, autobiografias, etc.; inéditas y referentes a la historia del antiguo reino de Valencia. Anales del Instituto general $y$ técnico de Valencia. t. IV, (1919), pág. 17. 
tants càrrecs en l'administració municipal, havent segut no sóls testics sino tambe actors de molts fets que conten, lo que dona mes seguritat a les sues noticies" (4). El mismo pone en entredicho la identificación que establece Almarche con el libro del bien y del mal (5) y puntualiza la cuestión del autor (6). El redactor del primer período (1308-1492) y el último (1642-1644) serían desconocidos. El resto lo atribuye a distintas manos: Frances Joan (1492-1535), Frances March (7) (1535-1616) y Joan Lucas Ivars (1628-1642) (8).

Carreres afirma, asimismo, para resaltar su importancia, que la mayor parte de los historiadores del siglo pasado lo tomaron como fuente y que este libro de memorias ha servido "de cap patró per a diferents dietaris, fets a imitació del mateix, abreviant unes noticies, suprimintne altres i afegintne tambe algunes" (9).

En relación al tema que aquí nos ocupa podemos afirmar que, fundamentalmente, aporta noticias indirectas y tardías, factores lógicos si tenemos en cuenta que la primera parte, la más interesante al fin propuesto -orígenes de la Generalidad y primeros años de funcionamiento-, es un resumen de Manuals de Consel/s y como dice su editor sólo después de 1488 sería obra personal de los sucesivos dietaristas (10).

La primera noticia, referida a los diputados y bastante escueta, es de 1410. Carreres la amplía al transcribir la sesión del Consejo donde se decide sobre la embajada que debe remitirse al rey para asesorarle en el nombramiento de heredero. El Pleno resuelve teniendo en cuenta, la solicitud hecha a los diversos estamentos, villas y ciudades y el documento elaborado por las fuerzas vivas implicadas, entre las que se incluyen los diputados del General, «tenia e clohia effecte que los dits Deputats no havien offici ne poder a fer missatgeria per tots los Esta-

(4) CARRERES ZACARES, S., introducción al Libre de Memories, pág. VIII.

(5) ALMARCHE Y VAZQUEZ, F. Op. Cit. Págs. 29-43.

(6) XIMENO, V., en Escritores del reyno de Valencia chronologicamente ordenados desde el año MCCXXXVIII de la Christiana conquista de la misma ciudad hasta el de MDCC. $X L$ VII. Valencia 1747-1749, t. II, pág. 350, lo encuadra entre los anónimos. FUSTER, J.P., en Biblioteca valenciana de los escritores que florecieron hasta nuestros días y de los que aún viven. Con adiciones y enmiendas a la de $D$. Vicente Ximeno. Valencia 1827-1830, t. l, págs. 184-185 lo atribuye a Francisco March y Juan Lucas Ivars. ALMARCHE Y VAZQUEZ, F. Op. Cit. Pág. 41, por su parte señala que del primitivo Libro del Bien y de/ Mal, redactado por los escribanos del Consejo, se han derivado multitud de copias.

(7) Este autor desempeñó además del cargo de jurado el de diputado de la Generalidad. FUSTER, J.P. Op. Cit., t. I, págs. 184-185.

(8) CARRERES ZACARES, J. Op. Cit, pág. XVIII.

(9) Ibidem.

(10) lbidem. 
ments ne per algun daquelles, ne podien donar ne despendre moneda del dit General sino en fer quitaments dels censals carregats, e que lo lur offici era limitat durador a certs anys e nopus, de que fon protestat per lo perjuhi ques causava a la ciutat e encara a tots los dits Estaments si ells volien fer coses de participi de la dita missatgeria" (11).

El protesto, pues, establece para estas fechas la temporalidad del organismo. Sus funciones, según esto, serían más económicas que representativas.

Los gastos de los mensajeros enviados corren a cargo de los remitentes «e no pas lo General del dit Regne, e aço per tolre perpetuitat o allongament de aquell» (12).

Este intento, evitar su funcionamiento como institución permanente, no será conseguido. Las Cortes de 1418 legalizarán su consolidación definitiva.

Su estructura económica apenas se adivina en el debate entre los representantes de València y Xativa, sobre un derecho comprado a la Generalidad (13) y en el acuerdo de los jurados solicitando su colaboración con el rey para el asedio de Bonifaci (14).

Otros detalles, sobre el organismo, se encuentran en los capítułos acordados por los tres brazos para nombrar los representantes valencianos en el Parlamento general, que debe dilucidar la cuestión sucesoria (15). Los de mayor interés son los referidos al apartado económico (16). Pero no se recoge en esta fuente sólo datos referidos a su estructura administrativa sino que también algunos de sus objetivos

(11) Libre de Memories de diversos sucesos e fets memorables e de coses senyalades de la ciutat e regne de Valencia (1308-1644). Valencia 1930, pág. 331.

(12) /dem, pág. 332.

(13) Idem, pág. 334 .

(14) /dem, pág. 486 (22.12.1420).

(15) Idem, págs. 354-362. Estos capítulos han sido transcritos por CARRERES de Manual de Consells.

(16) Idem, págs. 357-358 "que les dites peccunies poden esser haudes en aquesta manera, ço es, qui per tal com bonament nos pot hom ajudar al present del General del dit Regne, obstant les provisions e obligacions sobre aço fetes, per les quals nos pot toquar en aquell ni bonament se pot allargar ni mudar lo temps del dit General, e que tots los dits tres Braços concordablement manleven les quantitats necessaries a pagar les coses dessus dites, ab tal condicio que en lo primer donatiu quis haura a fer al senyor Rey, com lo haurem, $o$ en la primera despesa general ques haura a fer per tot lo dit Regne, per qualsevol necessitat per aquesta rao manlevada, se haja a encorporar o ajustar en lo levament ab o en lo dit donatiu o despesa, e que aquesta quantitat ab aquella se leu, es haia, en la forma e manera que sera lavors acordada". Siguen algunas condiciones previas sobre el mismo. 
quedan reflejados en ella: las tropas enviadas al rey en el sitio de Balaguer fueron pagadas durante tres meses del dinero de la Generalidad (17). La petición del rey, para hacer frente a los gastos ocasionados por la rebelión del conde de Urgel y su próxima coronación, pone en evidencia sus limitaciones. A través del baile, Juan Mercader, solicita al Consejo que reunidos los tres estamentos le concedan de los fondos del general quinientos jinetes pagados por un mes. El Consejo contesta negativamente porque "seria necessari fer ajust dels III Estaments del Regne, lo qual ajust, ultra la sua dificultat de esser fet, conte repugnacio de Furs e privilegis" (18). La Diputación queda así enmarcada dentro de sus propios límites como delegación del General sin autonomía propia. Sus fines aprobados en Cortes sólo podian ser modificados por una reunión del mismo rango.

Las noticias hasta el siglo XVI, tal como hemos visto, surgen principalmente alrededor de la problemática planteada por el interregno. A partir de 1500 aumentan las referencias a los diputados relacionadas con el ceremonial (19). La intervención de Frances March, diputado de la Generalidad (20) en su redacción determina la mayor amplitud en el número y aspectos tratados. Sin faltar descripciones de ceremonial en las que intervienen los diputados (21), se reseñan además, en ocasiones, el nombre de los titulares responsables (22) y asuntos relacionados con su gestión: pleitos (23), incompatibilidades (24). Los temas económicos, relacionados con los impuestos, también encuentran eco en el dietarista (25).

La estructura administrativa, cuyos cargos han ido apareciendo a lo largo del relato, queda recogida de forma orgánica para 1598 con ocasión del duelo organizado por la muerte de Felipe II (26).

(17) /dem, pág. 425-426.

(18) Idem, pág. 428. Acuerdo de Manuals del 9-12-1413.

(19) Idem, págs. $750,763,812,829$. Recepción y pompas fúnebres de reyes y altos dignatarios.

(20) Su autoria se puede apreciar en algunas de las citas de este mismo articulo, ver nota 78 y 81.

(21) Libre de Memories, págs. 843, 929, 932, 933, 1.038, 1.079, 1.088.

(22) ldem, págs. $1.000,945$.

(23) ldem, págs. 1.007.

(24) /dem, págs. 1.012, 1.015.

(25) ldem, pág. 954.

(26) $/ d e m$, pág. 1.037 . 
Almarche (27) y Carreres (28) califican esta obra como una de las copias del Libre de Memories. Roque Chabas publicó las noticias que proporcionaba el manuscrito, aunque descartó las listas de jurados, justicias y otros cargos municipales (29). Su fecha de inicio es 1306 para concluir en 1774. Esta fuente proporciona datos más bien escuetos y de diversa índole: infortunios, construcciones, nombramientos, etc. Hay que resaltar que las referencias a la Generalidad, más bien escasas, aluden a dos aspectos: administrativo (30) y económico (31). A pesar de que se da noticia de construcciones; en 1331 se pone la primera piedra del campanar de la Seu, o comienzo de funcionamiento de algunos cargos: 1324 comienza a ejercer su oficio el justicia de 500 sueldos, 1377 el racional. Ni el organismo ni el edificio, que lo albergó ya en el siglo XV, merecieron la atención del dietarista.

\subsubsection{Libro del Bien y del Mal (1306-1646)}

Ha sido publicado por Doñate manteniendo el título del manuscrito (32).

Su contenido se divide en apartados independientes y desiguales dedicados a recoger los titulares del cargo de jurado, justicia civil, justicia criminal, justicia primero de 50 sueldos y a partir de 1340 de 300 sueldos. Finaliza con el elenco de Cortes celebradas de 1370 a 1646. Los datos han sido extraídos totalmente de Manuals de Consel/s (33). Por su contenido, justamente lo desechado en el apartado 1.1.1, no hay

(27) ALMARCHE Y VAZQUEZ, F. Op. Cit., pág. 43.

(28) CARRERES ZaCARES, S. Op. Cit,, pág. XXVI.

(29) Fastos Valentinos. El Archivo II (1887-1888), págs. 72; 95-96; 119-120; 143-144; 168; 191-192; 216; 247-248; 287-288; 317-320; t. III (1888-1889) págs. 24; 48; 143; 191; 239-240; 263-264; 402-408.

(30) Fastos Valentinos. El Archivo. T. II, pág. 320, recoge las incompatibilidades de los asesores, acordadas por el consejo General en 1592-93, de forma muy similar al Libre de Memories.

(31) Idem, t. III, pág. 24 «En este any [1604] se posa impost en los naips, sombreros, sal y neu pera sustentar cuatre Galeres pera guardar la costa. Este any el General vell se ajusta en lo nou de les Corts". Esta noticia no se recoge en el Libre de Memories.

(32) A requerimiento de don Antonio Llorens é Ivañez, generoso, é idalgo de sangre, se escrivió este libro intitulado del Bien y de/ Mal; siendo clavario del Sto. Hospital Real y general de esta ciudad de Valencia en el mes de agosto del año 1776. Ligarzas N..$^{\circ}$ (1976) págs. 5-164.

(33) Idem, pág. 115 "todo lo qual se halla extendido en los libros custodidos en el Archivo de dicha ilustre ciudad". 
duda que está relacionado con otros manuscritos señalados por Almarche como copias del Libre de Memories: Lista de jurados y Cortes (34), Libro de Memorias de Valencia, del Conde de Cocentaina (35). A partir de las noticias referidas a los epígrafes mencionados, no da otras informaciones si exceptuamos la legitimación de hijos naturales a partir de las Cortes de 1547.

Visto el fruto, más bien escaso, del análisis de ambas copias, nos ha parecido inútil insistir en el resto.

\subsection{Dietari del Capella d'Anfos el Magnánim}

Según su editor es «una de les mes interessants cróniques valencianes quatrecentistes» (36). Este como el Libre de Memories ha sido utilizado por los sucesivos historiadores valencianos desde Escolano, Ribelles, Teixidor, Mayans. Sanchis Sivera tomó para su publicación una copia conservada en la Biblioteca Universitaria de 1742 que confrontó con el original calificándola de "copia prou aceptable" (37). Su editor, tras cuestionar la paternidad atribuida a Guillem Vidal por Mariano Ortiz, siguiendo las pistas aportadas por la propia crónica, da por resuelta la identidad de su autor. A su juicio sería obra de Melchor Miralles que pudo ser hijo de algún servidor del rey o patrón de alguno de sus barcos. La calificación que le merece queda reflejada en el prólogo al mismo «El Dietari es un llibre sens pla ni orde de cap mena. L'autor ni es escriptor ni te condicions d'historiador: el su estil es dur, pesat, sec y desalinyat" (38). Asimismo señala las fuentes generales y locales que sin duda le sirvieron de base (39). Su contenido es dividido en partes. «La primera part apenes te interes históric, per qués limita a reproduir lo que diuen les croniques de l'arquebisbe de Toledo i de Sant Joan de la Penya, $i$ alguns altres manuscrits: la sola novetat es un afegito d'estadistica referent a les viandes que s' consumien a Valencia. La segona part, que com la primera te el seu prólec, comença des del pricipi del mon, i porta un catálec de papes que arriba fins a Calixte III... La terça part es ja més interessant, no obstant portar moltes coses estracta-

(34) ALMARCHE Y VAZQUEZ, F. Op. Cit., pág. 46.

(35) Idem, pág. 44. DOÑATE, por su parte, señala que nada parece oponerse a que el libro sea una copia del que se encontraba en manos del conde de Cocentaina.

(36) SANCHIS SIVERA, J., introducción al Dietari del capellá d'Anfos el Magnanim. Valencia 1932, pág. VII.

(37) /dem, pág. Vill.

(38) /dem, pág. XIX.

(39) ldem, págs. XX, XXI. 
des de la primera part, pero parla d'altres de Valencia, mes vistes per ell i altres preses de diverses memories... El llibre, a partir d'aci no te desperdici. Les quatre parts següents, dividides per nosaltres, per que l'autor les porta com a continuació de l'anterior, constituixen un troç d'historia vixcuda i admirada per l'escriptor» (40).

Al fin que aquí nos ocupa, y según la división establecida de su contenido, la primera y segunda parte de carácter más general no recoge ninguna noticia de interés. La tercera centra más su atención a los sucesos acaecidos en Valencia de diversa índole. La más interesante a nuestro propósito era la cuarta parte aunque las noticias aportadas son menores en cantidad e importancia a las recogidas en el Libre de Memories.

De las siete subdivisiones que establece Sanchis Sivera sólo a partir de la cuarta se refiere a Valencia. A lo largo del cuarto, quinto y sexto apartado se relatan hechos relacionados con Valencia: sentencias, homicidios, catástrofes naturales o sociales, etc. Los diputados sólo serán mencionados de forma esporádica y ya bastante tarde - 1459_. Motivo, la entrada del rey don Juan ue los diputats se vestiren de morat florenti, e axi mateys larchs fins en terra" (41). No hay otras menciones en festejos similares.

La séptima parte dedicada concretamente a Valencia - Memorial d'actes pasats a Valencia- resulta también estéril al tema.

Aunque se recogen nombramientos de otros cargos: notarios, racional. Su fecha final 1478 no justifica tampoco esta ausencia; para entonces, la institución, como órgano permanente y con sede propia, lleva años de funcionamiento.

\subsection{Libre de Antiquitats (1472-1680)}

Fue editado también por Sanchis Sivera en 1926 (42) a partir del manuscrito que se encontraba en la catedral con letra de los siglos $\mathrm{XVI}$ y XVII.

Según su editor el manuscrito era obra de diversos autores. El primero, Pedro Martín, beneficiado de la catedral, nos legó la mejor parte del libro hasta 1540 "su estilo es claro, y elegante y el idioma es castizo puro y correcto" (43).

(40) ldem, pág., XXII.

(41) Dietari del capellá, pág. 225.

(42) Libre de Antiquitats. Manuscrit existente en el archivo de la catedral de Valencia. Valencia 1926.

(43) Idem, pág. X. 
Según Sanchis Sivera "no es... una crónica o dietario como los que de ordinario se escribian en la Edad Media, colección de notas más o menos interesantes, cuya mayor importancia estribaba en la cronología, si el autor es contemporáneo, pues contienen frecuentemente muchos errores por haberse recogido del rumor público o de testigos noveleros. Nuestro libro está constituido por una serie de relatos escritos por testigos presenciales, de gran cultura y de completa veracidad, por haber intervenido en ellos directamente" (44).

A pesar de esta afirmación García Cárcel señala que «la transcripción del manuscrito, impreso en 1926, deja mucho que desear, tiene varios errores" (45).

El hecho de que sus autores eran todos sacerdotes relacionados con la catedral, condiciona indudablemente su temática. Los hechos que narra inciden fundamentalmente en las noticias más próximas a ellos.

El libro comienza en 1472 y no tiene un orden cronológico hasta 1519.

En relación al tema que nos ocupa, sólo una mención a los diputados cuando se establece el ceremonial establecido para la entrada del cardenal Borja en Valencia "los diputats del Regne el portaren fins al portal dels Serrans" (46).

\subsection{Libro de Memorias de Guillem Mir (47)}

Este manuscrito se encuentra en la Biblioteca Universitaria de Valencia todavía inédito (M-255). Gutiérrez de Caño sugiere tres autores: Guillem Mir, del que toma el nombre (1306-1491), Luis Masco (14921503) y Burrull (1503-1705) (48).

Almarche considera que, aunque el manuscrito no seria el original, es la copia más antigua (49).

Fuster, por su parte, afirma que el primer autor empezó esta obra en 1484 y la concluyó en 1492 (50).

Comienzan las noticias en 1306. Su base, como es normal en este

(44) ldem, pág. VII.

(45) GARCIA CARCEL, R. Las Germanias de Valencia. Barcelona 1981, pág. 21.

(46) Libre de Antiquitas, pág. 1.

(47) GARCIA CARCEL, R., Op. cit, , pág. 22, lo denomina bajo el epígrafe de Fastos Consulares.

(48) GUTIERREZ DEL CAÑO, M., Catálogo de los manuscritos existentes en la Biblioteca Universitaria de Valencia, N. ${ }^{\circ} 1.492$.

(49) ALMARCHE Y VAZQUEZ, F. Op. Cit., pág. 75.

(50) FUSTER, J. P. Op. Cit. T, I, pág. 37. 
tipo de escritos, Manuals de Conse//s. Fundamentalmente, y según esta fuente, como el Libro del Bien y del Mal, reseña los ocupantes de los distintos cargos de la administración municipal. Hasta 1331 no se hace otro tipo de referencias. Estas aunque breves siguen la dinámica de los anteriores: construcciones, catástrofes, pestes, terremotos, etc.

Relativo al tema que tratamos, nuevamente una referencia poco significativa en 1413 (51).

El resto del manuscrito, debido a otros autores, sigue la misma estructura: cargos y noticias diversas. Estas serán sin embargo, escasas y su desarrollo no superior a una línea, a partir de 1520 estarán relacionadas principalmente con Germanias y Moriscos.

\subsection{Dietario de Francisco Joan (1306-1535)}

Según Almarche el original se ha perdido (52). Las dos copias que han llegado a nosotros se encuentran una en la Biblioteca Universitaria hecha por Borrull en el siglo XVIII y otra del siglo XVII en la de los dominicos. Hemos consultado la que se custodia en la biblioteca (m197).

Este autor, como tantos otros, se basa en Manuals de Conse//s Fuster afirma que a partir de 1490 refiere sucesos presenciados personalmente (53).

La copia guardada en la Biblioteca Universitaria es incompleta. El mismo copista afirma que sólo toma nota de aquellas noticias que le parecieron más interesantes (54).

Aquí como en libros de similares características se recogen pestes, conflictos sociales, fiestas, construcciones, etc.

Sobre el tema que estudiamos sólo una referencia para 1406 «que de la pecunia del General fossen emprestats al senyor Rey dos mil florins pera son viure e obradors del donatiu al dit senyor rey faedor" (55).

De los manuscritos consultados es de los más ricos en aportaciones, no sólo relata el hecho, sino que anota comisiones, cuentas, relatos de batallas, en lugar de simples y esquemáticas noticias.

(51) MIR GUILLEM, pág. 28 v. "Los honorables diputats hagueren semblant lletra del honorat $\mathrm{m} .^{\circ}$ Aznar Pardo de la Casta", en ella se les comunica la toma de Balaguer por don Fernando.

(52) ALMARCHE Y VAZQUEZ, F. Op. Cit, pág. 83.

(53) FUSTER, J.P. Op. Cit., t. II, pág. 524.

(54) Dietario de Francisco Joan, pág. $1 \mathrm{v}$.

(55) Dietario de Francisco Joan, sin foliar. 


\subsection{Libros de jurados y oficiales de Valencia}

Almarche opina que esta obra de Esquerdo debe incluirse entre las abreviaciones de Mir o de las memorias de la ciudad de Valencia (56).

Su autoría no admite dudas; al contrario que en otros manuscritos, el dietarista se menciona claramente en el transcurso de su desarrollo, eliminando cualquier vacilación. Muerto en 1699, el final del libro se debe a otro autor como se puede apreciar claramente en la letra.

El libro forma parte de los manuscritos de la Biblioteca Universitaria de Valencia $(\mathbf{M}-19)$.

Su contenido, tal como establece su autor, comienza en 1306. Escrito a doble columna, sin foliar, recoge la nómina de funcionarios dependientes del municipio: jurados, racional, mustasaf, etc. Los virreyes y otros cargos de denominación real no empiezan a registrarse hasta principios del siglo XVII.

A mediados de ese mismo siglo comenzarán a consignarse otro tipo de datos. Estos, aunque escuetos, están dentro de la tónica seguida por el resto de los dietarios.

Relativo al tema que estamos rastreando, y a pesar de que su autor, según Ximeno, desempeñó determinados empleos de la diputación (57), sólo hemos encontrado una mención en relación a la muerte de un diputado (58).

La importancia de este manuscrito radica, sin duda, en la afirmación de Almarche que lo califica como el catálogo de jurados más completo que poseemos (59).

\subsection{Datos aportados por los dietaristas}

Según lo expuesto y de acuerdo a los dietaris consultados, podemos establecer que la repercusión de la institución en la sociedad de su época no alcanza en ningún momento excesivo relieve. Las noticias aportadas por los distintos dietaristas son escuetas y muy limitadas.

Si exceptuamos el Libre de Memories del que nos ocuparemos posteriormente, en su mayoría no aportan excesivos datos. El libro del Bien

(56) ALMARCHE Y VAZQUEZ, F. Op. Cit., pág. 307.

(57) XIMENO, Op. Cit., t. 2, págs. 132-133.

(58) En 1681 expone que el ceremonial seguido a la muerte del racional es el mismo que se habia hecho con el jurado Francisco Soler: aque mori sent jurat y diputat y el diputats tambe feren demostracio per lo dit Soler tancant les portes y asistin a casa del difunt».

(59) ALMARCHE Y VAZQUEZ, F. Op. Cit., pág. 308. 
y del Mal no contiene ninguna referencia. El Dietari del Capella, Libre de Antiquitats y el Libro de los Jurados y Oficiales de Valencia, solamente una reseña ceremonial. El Libro de Memories de G. Mir recoge una comunicación a los diputados. Más interesantes son el Dietari de Francisco Joan y los Fastos Valentinos. El primero recoge una noticia económica y el segundo se extiende, aunque brevemente, al campo administrativo y fiscal.

Sólo el Libre de Memories ya mencionado permite, a través de su lectura una mayor aproximación a la institución.

Llegados a este punto convendría tener en cuenta lo expuesto por su editor: "no es possible qu'el primitiu original estiguera com ha arrivat fins nosaltres ab moltes noticies truncades, altres errades $\mathrm{i}$ altres de tal modo redactades que sense l'auxili dels Manuals son incomprensibles" (60). A fin de subsanar estos problemas, Carreres recurre a la publicación paralela, en ocasiones, de los acuerdos anotados en Manuals de Conse//s. Estas anotaciones, sin duda, ayudan a comprender el sentido del libro en más de una ocasión; pero aportan noticias que no se pueden asegurar estuvieran contenidas en el original. Por ello, nos ha parecido oportuno un estudio más minucioso que el realizado en el apartado 1.1. Aquí sólo se reseñarán las noticias aportadas por el original, tratando de extraer del mismo todos los datos interesantes al conocimiento de la institución.

La primera apuntación es de principios del siglo XV. Todavía la institución no ha adquirido el rango de permanente, pero el momento es crítico y la actuación del organismo definitiva para su posterior desenvolvimiento.

Los diputados son mencionados en 1410 , en relación con la embajada a remitir al rey Martin para su asesoramiento sobre la sucesión, como un componente más de las fuerzas en las que recae la responsabilidad del país (61). La noticia, según puede verse, sin el complemento de Manuals, ofrece menos soluciones al fin propuesto. Ese mismo año se recogerá una cuestión planteada entre los representantes de Xátiva y Valencia relacionada con el General. Los jurados valencianos, que han comprado un derecho de la Generalidad en el que se comprende Xá-

(60) CARRERES ZACARES, S., Op. Cit., pág. XVIII.

(61) Libre de Memories, pág. 331. "Que fos feta misatgeria al Senyor Rey En Marti, en Barcelona, per part de tots los staments y Diputats per suplicarli volgues declarar a qui pertanyen los Regnes de Arago, apres sos dies, per no tenir succesor. Hon esta llargament deduhyt com foren ajustats tots los Staments en la Cofraria de Sent Jaume, nobles homens, ciutadans e altres e los Diputats". 
tiva, reclaman su derecho (62). El problema de la sucesión, todavía sin resolver al año siguiente, obliga al Consejo a establecer una serie de disposiciones con el fin de pacificar la ciudad. Una de ellas atañe a los fondos de la Generalidad (63). El dinero del organismo se empleará asimismo para hacer firme la sentencia dictada por los compromisarios en Caspe (64).

No se dan más noticias hasta comienzos del siglo XVI, así pues, de los testimonios recogidos, no se puede afirmar que en la Edad Media la institución alcance mucha repercusión en la vida cotidiana. Sus impuestos, múltiples desde los primeros momentos, serían por lo común aceptados sin controversias.

La guerra de «los Dos Pedros» entre Castilla y Aragón, 1356-1369, había convertido lo extraordinario en ordinario.

De lo expuesto, pues, se puede deducir que los Diputados, como máximos representantes del organismo de que forman parte, son un cargo independiente de los distintos estamentos y son convocados como una fuerza más a la hora de solventar un conflicto planteado.

El resto de cuerpos que forman la plantilla de la institución queda, para esta época, en el más completo anonimato.

Las referencias a su estructura, no se puede decir que sean mucho más amplias que las referidas a la administrativa. De ellas se puede entresacar que el General suele vender alguno de sus derechos, que es temporal, y como tal, sus objetivos están regulados por los parlamentarios de los tres brazos reunidos en cortes, y que entre sus fines se encuentra subvencionar ayudas militares al rey.

La Edad Moderna será más prolija no sólo en datos, sino también en detalles, que ayudarán a comprender un poco más la institución en sus diversos aspectos administrativos, económicos, representativos, etc.

Desde principios del siglo XVI se reseña la intervención de los dipu-

(62) Libre, pág. 334. "...en demanar part a la Ciutat de la stima de fustes de mar e armes e jarcia e maçareses de la Tarazana que esta dins aquesta ciutat, les quals coses solien ser del General del Regne de Valencia, [quin feu venda a la ciutat de Valencia] en los dies pasats, en lo qual General, Xativa devia ser compresa. Lo Consell ho acomana als honrats Jurats e Advocats que fesen ço quels paregues esser just, bo e rahonable».

(63) Libre, pág. 371. "Lo Consell fonch de opinio que la ciutat e lo Regne devia proposar que les pecunies del General antich fossen convertides en les necesitats que lo Regne [ha] per fer les despeses acercar e saber qui es Rey e Senyor nostre, [e per dur aço a effecte, los sindichs de la Ciutat qui entrevenen en lo General Parlament deuen instar e proseguir, com alguna altra manera no sin facil e presta, haver monedes a aço e per ço que dit es]".

(64) Idem, pág. 425. "Com foren fets trescents rocins, sots capitania del Duch de Gandia, en socors del Senyor Rey en lo siti de Balaguer, e foren pagats de la pecunia de la Generalitat per tres mesos". 
tados en determinados actos. Estas son las referencias más abundantes; no faltan sin embargo las relacionadas con otras cuestiones.

La primera noticia, situada por el cronista en 1507, se refiere al recibimiento hecho por los diputados a don Fernando y doña Germana que arriban a Valencia procedentes de Nápoles (65). Seguirá, en 1516, la actitud de los mismos ante la muerte del rey (66). Al año siguiente y con ocasión de un hecho esporádico pero no inusitado, el desbordamiento del río Turia, se hace alusión de los fondos de la Generalidad (67).

Los diputados, a pesar de lo dicho, no son mencionados en todos los recibimientos reales; sirva como ejemplo el de 1528, hecho a Carlos $\checkmark$ con ocasión del juramento de los Fueros (68). Ese año sin embargo se reseñará el palacio como lugar desde donde el emperador presenció la fiesta del Corpus (69). La muerte de doña Germana en 1536 pone en movimiento nuevamente a los diputados que deciden observar el duelo establecido (70). Las noticias relacionadas con el ceremonial continúan en 1539 con el recibimiento hecho por los diputados a don Jorge de Austria, arzobispo de Valencia (71). En esta ocasión y para el mismo acto, se menciona también la diputación (72).

Habrán de pasar varios años antes de que se registre una nueva

(65) Libre, pág. 750. "Y los Diputats del Regne de Valencia ab una barca molt ataviada, vestits ab tabardos de vellut morat, forrats de seti carmesi, y los galiots vestits de colors entraren molt dins mar a besar les mans a S. M. e a la Reyna".

(66) Libre, página 763. “Los Diputats ab tots los Officials de la Diputacio se vestiren de marrega, y pasat lo Capell ardent se vestiren de gramalles y caperons de dol".

(67) Libre, pág. 775. «Dit any, dia dels Sants Metges, a 27 de setembre, vingue lo Riu de Valencia a les tres hores pasat mig jorn molt gros y tan gros que derroca lo Pont dels Serrans y lo del Real, que no restaren sino los peus de dits Ponts, y tambe derroca lo Pont nou, lo qual apres a tornat a rehedificar la Diputacio a ses despeses per lo acte inopinat".

(68) PINILLA P. DE TUDELA, R., E/ virreinato de $D .{ }^{a}$ Germana de Foix $y D$. Fernando de Aragón, duque de Calabria, (1526-36). Fin de una revuelta y principio de un conflicto. Tesis doctoral, inédita, Valencia 1982.

(69) Libre, págs. 812-813. «Los Diputats suplicaren a sa Magestat volgues venir a veure la festa a la Diputacio; donarentli molt bella collacio, que consta 300 Is.".

(70) Libre, pág. 829. "Los Diputats vent que los Jurats se eren vestits de dol, per servar los actes de Cort, se vestiren tots los officials de la casa ab tres gramalles, costa lo dol mes de 800 Ils. per acte de Cort."

(71) Libre, págs. 842-843. "E ans de arribar a S. Antoni, los senyors Diputats del Regne de Valencia ab tots los officials de la Diputacio li feren recebiment."

(72) Libre, pág. 834. “Entra la processo per lo portal dels Serrans e per lo carrer dels Serrans, lo qual estava molt ben empaliat ab moltes banderes y estandarts dels Officis, fins a la Diputacio, e la processo torna a la seu e entra per la porta dels Apostols." 
anotación relacionada con la institución que estudiamos. En 1565, será un relámpago el que ponga de actualidad el edificio (73).

La primera repercusión de los impuestos cobrados por la Generalidad se da en 1583 con ocasión de la reducción del Tall de/ drap, aumentado en 1428, a su primitivo valor de 12 dineros por libra y cuyo pregón recoge el dietarista (74). En esta fecha se menciona por primera vez el nombre de cuatro de los diputados. En este avance cronológico que estamos efectuando, nuevamente el edificio será mencionado en los festejos organizados a la entrada de Felipe II en 1586 (75). Otro hecho accidental ese mismo año, un gran incendio, convierte la torre de la diputación en cárcel (76).

A partir de este momento y hasta finales de siglo, las noticias aumentan su interés: se reseñan los nombres de los diputados que juran su cargo para 1587 (77); la disputa establecida en 1589 entre los jurados para ocupar la plaza de diputado ostentada generalmente por el jurat en cap (78); las incompatibilidades en el cargo de asesor (79); se

(73) Libre, pág. 883. "A 17 del mes de Agost, dit any, vingue tan gran tempestat de aygua, trons y lamps en la present ciutat, que caigueren dins Valencia quatre llamps: la hu en la casa del General...».

(74) Libre, págs. 954-955. "...fon feta crida per la present ciutat de Valencia, de part dels senyors diputats del present Regne, que per quant en Corts celebrades per lo senyor Rey Don Alfonso..., en la vila de Molvedre al present Regne en lo any 1428, foren afigits nou diners al dret del general del tall per certa ocorrencia de temps, ço es, que axi com se pagava un sou per lliura de diners se hagues de pagar un sou y 9 diners, ara per los respectes ben vist a Sa Magestat y als senyors diputats suprimixen dit dret en quant als nou diners tansolament, los quals de 12 del present en avans no se hajen de pagar; la qual crida fon feta essent diputats los illustres y molt Reverents Don Alonso Zanoguera, Mos. Cristofol Artes. En Frances Geroni Mascarell, per mort de En Nicolau Vernegal, e En Lluis Perez de Oriola,"

(75) Libre, pág. 980. «Aquella nit ensengueren la ciutat y tota la muralla y torres que del Palacio Real se podien descubrir y en particular la Diputacio se aventaja molt en dita ensesa perque fon molt de veure y per la gran multitud de cohets que a la continua de la Torre de la dita cassa de la Diputacio tiraven; duraren les dites lluminaries quatre nits continues."

(76) Libre, pág. 989. "...los jutjes vent 10 gran infortuni obriren les presons y donaren llibertat a casi tots los pressos excepto alguns que estaven molt criminosos, los quals portaren part de aquells a la Torre del portal de Quart y part a la Torre de la Diputacio y part a la preso del St. Offici perque en altra manera tots hagueren perit."

(77) Libre, pág. 1.000. «Al primer del mes de Janer del any 1587 juraren per diputas del present Regne de Valencia, ço es, per lo Bras Eclesiastich: Io $1 I^{\mathrm{m}}$ y $\operatorname{Rev}^{\mathrm{m}} \mathbf{S}^{\text {or }}$ Don Juan de Ribera Patriarca de Antioquia y Archabisbe de Valencia, Don Martin de Ferreras del Orden de Sn Juan, Comanador de Torrent. Per lo Braz Militar: Don Francisco Centelles e Mos [hueco] Desprats, cavaller de Oriola. Per lo Braz Real: En Pere Juan Antoni Matheu, En Antoni Pedro de Morella, ciutadans".

(78) Libre, págs. 1.007-1.008. «En aquest any per ser estat mos. Geroni Abella clavari de la Diputacio del trieni antecedent, mos Gaspar Pellicer pretengue, com a Jurat segon, que ell 
incide sobre el mismo tema el siguiente año 1593 (80); el nombramiento de los cargos de la Generalidad que desempeñan los jurados plantea también algún problema en 1595 que el dietarista relata con bastante minuciosidad (81); la muerte de Felipe II -1598 - nos traerá nuevamente noticias sobre el ceremonial "Dilluns, apres dinar, que fon dit dia 5 de Octubre anarem tots los Officials de la Diputacio, engramallats, ço es, los sis diputats, sis contadors, tres claravis y tres administradors, sindich, assessor, escriva y subsindich, tots a cavall y engramallats, ab les maces cubertes de dol y les cares y caps cuberts, sols faltaren en aquest acompanyament dos officials y foren un diputat y un clavari que foren Mos Turruvio y yo Francisco March que per ser Jurats no poguerem anar no obstant que Turruvio era diputat y yo clavari» (82).

havia de ser diputat y no mos. Abella per ço que non erat definitiu e fon declarat per la Real Audiencia que mos. Abella estava impedit, e com la declaracio fon feta en favor del Jurat segon ana lo dia de capdany lo dit Pelicer ab los demes officials de la cassa a pendre posesio, e per quant hi havia pretencio per part de Don Jaume Ferrer, Comanador de Museros, dient que lo ser Llochtinent de Governador no era ympediment, y que axi ell havia de concorrer als officis de dita casa e com llavors no hi pogue haver declaracio per estar la litis pendencia no donaren lo jurament a ningu, diferintlo pera quant hi hagues.

Fou declarat que era impedit lo dit Don Jaume Ferrer, la qual declaracio porta lo honorable Don Antón Bellvis, Sindich del general, de la Cort de Sa Magestat hon era anat pera dit effecte e de alli sen ana lo dit Pellicer dia de capdany ys posa en lo llit malat e al cap de quince dies lo soterraren. Llavors lo Jurat Francisco March posa una escriptura davant la Real Audiencia dient que per quant estava donada aquella sentencia en favor de la segona cadira, la qual cadira ell ocupava per mort del dit Pellicer, que aixi li fos donada la posesio del dit offici de diputat y la sentencia Real fos executada e aixi fon fet $y$ declarat y yo Francisco March prengui la posesio del dit offici a 17 de abril de 1590 ".

(79) Libre, pág. 1.012. “En lo mes de Giner, 1592, fon fet establiment per lo Consell general que ningun advocat de la Ciutat pogues ser advocat de la Diputacio, ni del Sant Offici ni...".

(80) Libre, pág. 1.015. «A 24 de Janer de 1593 delliberacio del Consell de que no puguen ser advocats de la Ciutat los que son del Real Consell, ni assessor de la Diputacio, ni assesor del...".

(81) Libre, pág. 1.023. cen lo present any per quant Christofol Perez de Almaçan, jurat en cap, era Diputat del trienni antescedent pasava la veu a Lluis Honorat Fores y per ser deutor al General lo dit Fores pasava al Jurat tercer $y$ axi nomenaren a Thomas Turruvio per diputat.

Y per quant conforme a fur havia de bajar lo Jurat en cap per la sobredita raho al lloch del Clavari, aquell no volgue ser per quant en acabar de ser jurat se havia de posar en relligio, com ho feu, y axi prega als Jurats que lo lloch del Clavari que ell havia de tocar lo donasen a Mos Francisco March. Mustasaf que llavors era de la present ciutat, y axi se feu, y per contador a Miquel Juan de Camos y per administrador a Martin Perez Dalmazan, germa del Jurat; y axi vespra de S. Thomas los quatre Jurats ciutadans, en presencia de mi sobredit Francisco March y acceptant, feren acte en poder del escriva de la Sala nomenant a Mos Turruvio en diputat, a Mos Francisco March, clavari, a Mos Miquel Juan de Camos, contador y a Mos. Martin Perez Dalmazan en administrador".

(82) Libre, pág. 1.037. 
Como se puede observar sus datos escapan de lo simplemente anecdótico para ofrecernos la estructura administrativa del organismo. El ritual seguido en el funeral celebrado en la catedral no aportará nada nuevo si no es la descripción de los usos y costumbres de la época (83).

Las noticias que proporciona esta fuente, para el siglo XVI, clarifican fundamentalmente la estructura administrativa del organismo. Si comienza, como en el período precedente mencionando solamente a los diputados de forma general, a partir de 1516 aparecen también, aunque de forma genérica el resto de sus componentes. El número y brazo a que pertenecen los diputados se deduce del juramento hecho en 1587 -dos por brazo- Otros puntos también se van aclarando. No es posible desempeñar el mismo cargo en dos legislaturas consecutivas. Los jurados ostentan además funciones como la de diputado y clavario, las deudas incapacitan para el ejercicio de éstas. Poco a poco se perfilan el resto de cargos: en 1595, diputados, clavarios, contadores, administradores. Finalmente en 1598 queda como se ha visto, perfilada completamente la estructura administrativa.

El organismo está compuesto por los siguientes cuerpos: seis diputados, el mismo número de contadores, tres clavarios e igual número de administradores. Es fácil adivinar que estos cuerpos están formados

(83) Libre, pág. 1.038. «E com fon començada la missa entraren los Diputats ab tots los Officials de la cassa engramallats, los quals entraren per la porta dels Apostols y anaren dret a la capella major y entrant per la part de davant lo altar feyen son acatament al Virrey y als Jurats y sen exiren per la porta de davant la Sagrestia y per la porta del Palau del Archebisbe sen exien y tornaren a la Diputacio,"

(84) Libre, págs. 1.080-1.081. "Divendres a 16 de dits mes y any essent los Jurats, Comendatari de Racional que era lo Jurat en cap dels ciutadans, y los dos Sindichs ajustats en la Sala de la dita ciutat ymbiaren la embaxada als Diputats de la dita ciutat en la forma seguent: quatre verguers engramallats, Geroni Bayarri y Alonso Sunyer, ciutadans, Sindichs de la dita ciutat, engramallats, $y$ apres molt criats en capusos; de esta manera anaren a peu de la cassa de dita Ciutat a la cassa de la Diputacio y muntant la escala yxqueren al replanell primer de dalt del cap de la escalera quatre macers de la Diputacio ab les mases cubertes de dol y juntament yxqueren a rebrels misses Buenaventura de Cas, advocat de la Diputacio, y Don Pedro Bellvis, Sindich, y Geroni Llorens Ridaura y [hueco $]$ Vasiero, notari, subsindich y to escriva de dita Diputacio y los dit misser Cas, advocat, y Don Pedro Bellvis, Sindich, posaren en mich als dits Geroni Bayarri y Alonso Sunyer, Sindich de dita ciutat, y en esta forma entraren en la Sala de la dita Diputacio, hon estaven los Diputats seyts y engramallats per son orde, $y$ alsantse en peu reberen als dits Sindichs de la present ciutat, los quals se segueren en les cadires que estaven buides a la part esquerra de dits Diputats y lo dit Geroni Bayarri dona sa embaxada comvidant de part de dita ciutat a dits Diputats, respongueren que acudirien com sempre be acostumaven a dites funeraries y que agrayen molt a dita ciutat la bona correspondencia que els feya y alsantse tots se despediren y acompanyats dels matexos los dits dos Sindichs tornaren a exirsen y al cap de la escala es despediren dels dits Advocats y Sindich, Subsindich y Escriva de la Diputacio y sen tornaren a la Sala ahon tornaren la resposta als dits Jurats." 
por uno o dos representantes de cada uno de los brazos que componen las Cortes. La plantilla principal queda completada con el síndico, el asesor, el escriba, y el subsíndico.

Su estructura financiera no será abordada con tanta amplitud. Sin embargo sí se recoge algún dato. Su regulación está sometida a las Cortes. El balance de sus cuentas sólo será mencionado parcialmente a través de algunas de las partidas que lo componen. Entre los gastos sólo se citan los extraordinarios, los ordinarios, por afectar a su personal y actos relacionados directamente con su actividad, sin duda no son reseñados por su autor. En cuanto a sus ingresos sólo se resalta el General del Tall del drap de entre los múltiples impuestos dependientes de este organismo. Su tasa inicial, 12 dineros por libra, aumentada en las Cortes de Sagunto de 1428 en 9 dineros más, es reducida a su cuantía original en 1583.

Además de estas noticias y las relativas al ceremonial este dietario no aporta otros datos, si exceptuamos los referidos al edificio. Estos hacen más referencia al palacio como enclave que por sus caracteristicas arquitectónicas o representativas.

El siglo XVII, del que sólo se abarcan cuarenta y cuatro años, sigue la misma tónica en cuanto al ceremonial, que es más minucioso en sus descripciones, aunque menos rico en detalles interesantes (84).

La muerte de Felipe III servirá al autor para introducirnos en los diversos ritos, llevados a cabo en tales ocasiones, con mayor riqueza de matices de la utilizada hasta ese siglo.

Comienza con la invitación extendida por la ciudad a los diputados (85), para los diversos actos que se celebrarán (misa en la catedral y otros) y finaliza con el ritual acostumbrado en tales casos y descrito con anterioridad (86).

El edificio en esta ocasión será mencionado de forma accidental. Durante la visita de Felipe IV a Valencia se celebra la festividad de San Vicente Ferrer. La Diputación, lugar habitual de los virreyes para presenciar este acto, será utilizada ahora por el soberano (87). La última noticia es de 1641; los jurados envían a la Diputación, donde estaba reunido el brazo militar, al síndico del estamento real para informarse del poder dado por dicho brazo a sus elegidos. Dicho estamento con-

(85) Libre, pág. 1.084. “ltem, per lo Almodi anaren dret a la plaça de la seu y a la Diputacio y entraren per la porta principal y yxqueren per la porta que va davant la Ballia y en dites portes estaven engramallats los Officials de la dita Diputacio."

(86) Libre, pág. 1.088.

(87) Libre, pág. 1.116. "Sa Magestat la veu en lo balco de la Diputacio ahon la solen veure los Virreys". 
testó que enviará a sus síndicos para dar a la ciudad su respuesta (88). Así pues, y tal como ya expusimos, el siglo XVII, más minucioso en las descripciones ceremoniales, no aporta ningún dato a los ya dados para el siglo XVI, que ayude a un mejor conocimiento de la institución. Hay que señalar que el organismo seguirá vigente hasta su disolución en 1707 con el decreto de Nueva Planta.

\section{CRONISTAS}

Ocupa ahora nuestra atención la obra ejecutada por los denominados cronistas valencianos. Establecer su número es la primera controversia que se plantea. Mientras Castañeda y Ribelles califican de tales a Beuter, Viciana, Escolano, Diago, Llorente y Boix; Almarche, por su parte, no considera como tales sino a los cuatro primeros, y García Cárcel introduce entre ellos a Onofre Ezquerdo.

Teniendo en cuenta que el mismo Castañeda expone que "Boix, más que historiador, es un divulgador de la Historia valenciana" (89) y que la obra de Llorente, tal como se desprende de su conjunto y ha quedado reseñado en su edición hecha en 1980, es una guía donde este autor agrupa geografía e historia, etnografía, folklore, sociología, jurisprudencia, sin olvidar los aspectos artístico-monumentales de Valencia y su reino, hace que sigamos el criterio de centrar nuestra atención en los cuatro primeros: Beuter, Viciana, Escolano y Diago.

Almarche refiriéndose a su obra expone «que aún contando con los defectos de los antiguos cronistas y habiéndose dejado llevar de la corriente de autoridad que se concedió en España en aquella época, a los falsos Cronicones, la meritoria labor de estos historiadores, tomada en conjunto, es de un valor inapreciable, por el gran número de documentos que consultaron en los archivos en aquel entonces intactos y muchos de ellos desaparecidos por completo o destruidos en parte» (90).

Tratando de seguir el rastro de nuestra institución analizaremos cada una de las obras de estos cronistas, aunque en ocasiones nuestra búsqueda resulte estéril.

(88) Libre, págs. 1.336-1.337.

(89) CASTAÑEDA Y ALCOVER, V. Los cronistas valencianos, Antonio Beuter, Martín de Viciana, Gaspar Escolano, Francisco Diago, Vicente Boix y Teodoro Llorente. Discursos leidos ante la R. A. de la Historia 28 de marzo 1920. Madrid 1920, pág. 50.

(90) ALMARCHE Y VAZQUEZ, F. Op. Cit., pág. 9. 


\subsection{Pedro Antonio Beuter (1490/95-1555)}

Las incidencias de su biografía han sido recogidas por Castañeda y Alcover (91), Fuster (92) e Ivorra (93) las anotan también en el prólogo que hacen a la edición de su crónica.

Su obra histórica, según Sánchez Alonso «por su contenido entra en el capítulo de las historias nacionales" (94), que son propias de la época; publicada en 1538 es traducida al castellano por su mismo autor, que trata de justificar su postura en el prólogo a la misma (95). Beuter según Pitarch «entenia que la diversitat, politica i lingüistica, cedia el pas a la superior unificacio" (96).

La calificación que merecen las fuentes que utilizó es entendida por algunos autores como las propias de su siglo (97), por otros carece de sentido crítico en la selección (98).

Su obra (99) se inicia con la población después del diluvio y abarca hasta el reinado de Jaime I. Lógicamente, pues, no aporta ningún dato a nuestro estudio, ya que la institución que nos ocupa surgirá con posterioridad.

\subsection{Martín de Viciana (1502-1582)}

Sus datos biográficos han sido reseñados por Torres (100) y Castañeda (101). Torres afirma que comenzó su crónica a los quince años en 1517 y la terminó en 1566 (102).

(91) CASTAÑEDA Y ALCOVER, N., Op. Cit. 22-23.

(92) FUSTER, J., nota preliminar a la edición facsímil de la Primera part de la História de Valéncia. Valencia 1971.

(93) IBORRA, E., introducción a la Crónica de Pere Antoni Beuter. Valencia 1982, págs. 7-10.

(94) SANCHEZ ALONSO, B. Historia de la Historiografia española. Madrid 1947, t. I, pág. 380.

(95) PITARCH, V., Defensa de l'idioma. Valencia 1972, págs. 36-39 recoge la dedicatoria justificativa.

(96) /dem, págs. 31-32.

(97) FUSTER, J.P. Biblioteca Valenciana, t. I, pág. 93 y CASTAÑEDA Y ALCOVER, Op. Cit,, 23.

(98) SANCHEZ ALONSO, B. Op. Cit. t. I, pág. 381 e IBORRA, E., Op. Cit., págs. 16-24.

(99) Primera part de la Historia de Valéncia. Traducida y ampliada bajo el título de Crónica General de toda España y especialmente del reino de Valencia.

(100) TORRES, J. M.", El historiador Viciana. Nuestro estudio biográfico. Revista de Valencia, (1882) págs. 255-264; IDEM, Prólogo a la segunda parte de la crónica de Valencia compuesta por Martín de Viciana. Sociedad Valenciana de Bibliofilos. Valencia 1881, págs. $|\mathrm{X}-\mathrm{X}| \mathrm{t}$.

(101) CAStañeda Y AlCOVER, V. Op. Cit. Págs. 24-31.

(102) XIMENO, V., Op. Cit. T. I, pág. 167. Hace constar incluso los días. 
Su obra habria que encuadrarla, según Sánchez Alonso, entre las dedicadas a los antiguos reinos, "La unidad política nacional se hace compatible con la autonomía de los antiguos reinos, y el pasado de cada uno, aún en lo posterior a su absorción en la nueva España, es historiado independientemente" (103). Su crónica escrita en castellano tendrá faltas, según el propio autor, por esa misma causa «que por ser yo valenciano no escrivire tan polido Castellano qual se habla en Toledo" (104).

La Cronica de la inclita y coronada ciudad de Valencia consta de cuatro partes: la segunda, dedicada a la genealogía; la tercera a los condes de Barcelona y reyes de Aragón y de Castilla, seguida de una descripción de castillos, villas y lugares del reino de Valencia; la cuarta, dedicada a las germanías, ha sido calificada por Durán como "la relació més completa e imparcial dels fets amb inclusió d'abundant documentació» (105). García Cárcel, por su parte, la define como «el mejor filón historiográfico para estudiar la revuelta" (106); la primera parte, dejada para el final conscientemente, hubiera sido, en caso de conservarse, la más interesante para el fin que nos proponemos, ya que Castañeda señala que de su texto se desprende que «debía comprender la historia política y social de Valencia desde la época de sus primeros pobladores hasta principios del siglo XVI, así como una descripción de los edificios y organismos valencianos" (107). Su pérdida es pues para nuestro tema irreparable.

\subsection{Gaspar Juan Escolano (1560-1619)}

Los datos de su biografía han sido recogidos, como en casos anteriores, por Castañeda (108). Según Sánchez Alonso, este autor y Diago se encuentran enmarcados en el período historiográfico 1592-1623 y «les caracteriza un cierto exacerbamiento del celo regionalista, que da tono polémico a las obras y daña a la veracidad cuando se trata el punto de los orígenes" (109). El mismo califica la crónica de Escolano

(103) SANCHEZ ALONSO, B. Op. Cit, t. II, pág. 2.

(104) VICIANA, M., Crónica de la inclita y coronada ciudad de Valencia, Ed. Facs. Universidad de Valencia, (1564-1972), t. III, pág. 10.

(105) DURAN, E., La guerra de las germanias i la seva interpretació Randa, N.o 1 (1975), pág. 29.

(106) GARCIA CARCEL, R., Op. Cit, pág. 26.

(107) CASTAÑEdA Y ALCOVER, V., Op. Cit, pág. 29.

(108) IDEM, Op. Cit, págs. 32-38; SANCHEZ ALONSO, B., Op. Cit., t. II, pág. 191, cita también a F. MARTI GRAJALES, El doctor Gaspar Juan Escolano, Cronista del Reino... Biografia (Nalencia 1892).

(109) SANCHEZ ALONSO, B., Op. Cit., t. II, págs. 162-163. 
como "obra de copiosísima información, atingente a todos los aspectos: historia política, natural, social, geografía, idioma, instituciones, instrucción..., con gran pormenor en las reseñas locales" (110).

Su estudio concebido en tres décadas queda de hecho reducido a la primera. Esta se encuentra dividida a su vez en dos partes que comprenden cinco libros cada una. El primero, que describe topográficamente el reino de Valencia, abarca hasta Sertorio; el segundo, la dominación primero romana, luego visigoda y finalmente musulmana; el tercero, lo dedica a la conquista de Valencia y su organización por Jaime I y Pedro III; en el cuarto enumera, emulando a Eximenis, las excelencias de Valencia; el quinto y último libro de esta primera parte está dedicado a la fundación de iglesias y monasterios. Los dos últimos, como podremos observar, serán los más interesantes para nuestro trabajo ya que recogen sendos capítulos dedicados a las rentas y forma y oficiales encargados de regir la ciudad y su reino.

La segunda parte, si exceptuamos el décimo libro dedicado a las Germanias y expulsión de los moriscos, ofrece en los cuatro restantes la descripción geográfico - histórica de las distintas ciudades que componen el reino.

Escolano es el que más datos aporta para el conocimiento de la institución que nos ocupa, influye en ello, sin duda, el hecho de que sea la Generalidad, a petición de las Cortes de 1604, la que se hace cargo de su salario de cronista y de los gastos de impresión de su obra (111).

Además de las noticias insertadas en la crónica, la dedicatoria hecha a los diputados en 1610 es harto significativa "que es llano, que quien es el escudo y protección de todo el Reyno, lo ha de ser de su Coronica universal y Coronista" (112).

Este autor, como ya expusimos, se ocupa de la Generalidad en los libros cuarto y quinto de su década. En el cuarto trata de sus orígenes, definición y derechos «La Diputación, que es un govierno de los tres estamentos, Ecclesiastico, Militar, y Real de todo el Reyno, tiene de recibo ordinario el derecho del General nuevo y viejo, que suelen rentar cosa de cien mil ducados, para la conservación de los fueros, y defensa del Reyno, en toda ocasión que se tratare de ofenderle. Los que ordenaron este derecho, le quisieron Ilamar General, porque no ay persona

(110) IDEM, pág. 191; CASTAÑEDA Y ALCOVER, V., Op. Cit., pág. 35 la califica como «la obra clásica de la historia de ese Reino [Valencia]".

(111) CASTAÑEDA Y ALCOVER, V., Op. Cit, pág. 34 recoge íntegra dicha petición.

(112) ESCOLANO, G. J., Década primera de la historia de Valencia. Ed. facs. Universidad de Valencia (1610-1972). 
exempta de pagarle, sino es en aquello que se toma para el culto de Dios. El General viejo començo a introduzirse algo antes de los años de mil quatrocientos. Después se puso de propósito en el de mil quatrocientos y tres; y con parte de lo procedido del sirvieron al Rey don Martín para desempeñarle de algunas deudas: como parece por los fueros que se hizieron en las Cortes de aquel año, que andan entre los Extravagantes. Al viejo se ha juntado el nuevo en las Cortes del año mil seyscientos y quatro, impuesto sobre Naypes, Sombreros, Sal, y Nieve, con designio de echar quatro galeras ordinarias en nuestro mar para guarda del, y de la costa" (113).

En el quinto, se refiere a la evolución de su estructura administrativa «Para la guarda y amparo de todo el reino eligen de tres en tres años seys Diputados, cuyo peculiar officio se emplea en la administración de las rentas y tributos impuestos para este fin: y conocen de los casos concernientes a ellos, y a la casa de la Diputación. Y por quanto dexamos escrito, que este Magistrado tuvo principio antes de los años de mil quatrocientos; conviene saber que se halla notado en el Archivo de la Ciudad, que en el de mil trescientos ochenta y dos, a postreros de Setiembre, prestó la Diputación al Rey Don Pedro el quarto de Aragón, diez mil florines. Estaria por aquel tiempo este officio en sus pañales, y como informe, y poco a poco le fueron perficionando, segun que en el año de mil quatrocientos y seys hallamos Diputados nombrados; que lo fueron el Obispo de Valencia, y Don Ximen Perez de Arenos, Mossen Iuan Pardo de la Casta Cavalleros; y Guillem Çaera Doctor en Leyes: Ios quales de conformidad, con Don Berenguel March, Maestre de la orden de nuestra Señora de Montesa, y de Ferrer Ram vezino de Morella, armaron una galera del dinero del General para cierto menester. Parece assi mismo que por todo aquel tiempo, y años despues, se nombraron ocho Diputados de cada Estamento, y se sacavan por suertes, para imponer el derecho del General. Otros tantos ponia de su mano y voluntad el Rey: hasta el año mil quatrocientos y diez y nueve, en que llego a su punto la casa de la Diputación, reynando el Rey Don Alfonso el quinto de Aragón. Entonces fue quando se reformó el numero de los Diputados, y se reduxo a dos de cada Estamento; y se nombraron los oficiales ordinarios de dicha casa, que son los Diputados, Contadores, Administradores, y Clavarios, los quales se mudan de tres en tres años: y el Abogado, Syndico, y Escrivano, que son perpetuos. La autoridad deste Magistrado es grande, y cosa de ver quando salen en publico con sus Lictores, o Maceros, que con ropas largas talares y unas maças

(113) IDEM, libro IV, columna N. ${ }^{\circ} 856 / 857$. 
muy grandes de plata dorada, les van delante. $Y$ es tan independente y absoluta la jurisdiccon de los Diputados, que como está dispuesto por fuero hecho en el año mil quinientos y diez, y decretado por el Rey Don Fernando, en la Rubrica de los Actos de Corte del General, capitulo treynta y tres. El Rey ni el Governador, ni otro official ordinario ni delegado, por grande poder que tenga, no puede entremeterse en las cosas contenidas en dichos Actos, ni en cosa que sea hecha por los oficiales de la Diputación en pleytos y puntos del General, nì en cosas incidentes, dependentes, o emergentes de aquellos; ni por via de simple querella, apelación, o recurso justo, o injusto, ni por causa recognoscendi; o por otra qualquier via y manera. Tambien se dio principio a edificar en el año mil quatrocientos y diezinueve, cerca de la casa de la Ciudad, la insigne casa de la Diputación, cuyos techos dorados de artificiosas entalladuras y maderame, con la sala de sus Ayuntamientos, pintada con las figuras de las personas de los tres Estamentos, y villas Reales que tienen boz en ella, es una de las cosas magestosas desta Ciudad» (114).

\subsection{Francisco Diago (1562/64-1619)}

Según Castañeda, que hace su biografía, de este cronista es de quien menos noticias biográficas ha podido encontrar (115).

Su concienzuda búsqueda de fuentes, como base de su obra histórica, ha sido resaltada por todos los autores que le dedican su atención (116). Sus anales (117), quedaron también reducidos a un solo tomo, dividido en libros. "En el primero nos da una descripción del Reino de Valencia con abundantes datos de Geografía histórica. En el... segundo trata del Reino de Valencia desde el Diluvio hasta la destrucción de Sagunto. En el... tercero desde la venida de los romanos hasta el nacimiento de Nuestro Señor Jesucristo. El cuarto desde esta fecha hasta la venida de los Godos a España. El quinto habla de los pueblos invasores, historiando la Valencia visigótica hasta la invasión de los árabes. El... sexto historia la Valencia árabe hasta la conquista del Reino por Jaime I de Aragón. El... séptimo y último se refiere a la Valencia cris-

(114) IDEM, libro $V$, columna 1.088/1.089.

(115) CASTAÑEDA Y ALCOVER, V. Op. Cit., pág. 38; GARGANTA, J. M. ${ }^{\text {a }}$, en el prólogo que hace a sus apuntamientos publicados por Acción Bibliográfica Valenciana (1936-42 hace también su biografía.

(116) XIMENO, V. Op. Cit., t. I, págs. 268-269; CASTAÑEDA Y ALCOVER, V. Op. Cit, pág. 42; SANCHEZ ALONSO, B. Op. Cit., t. II, pág. 192.

(117) Anales del Reyno de Valencia. Tomo primero, que corre desde su población después del Diluvio, hasta la muerte del Rey don Jaime el Conquistador. Valencia 1613-1972. 
tiana hasta la muerte del rey $D$. Jaime el conquistador» (118). Para Castañeda esta obra obedece «a un plan histórico-crítico, no llegando, sin embargo, en su composición al acierto que logró Escolano »(119).

La recopilación de materiales recogidos para el segundo tomo de los anales, que debía comprender de Pedro el Grande hasta Felipe III, fue publicada en dos tomos por Acción Bibliográfica Valenciana 1936$42(120)$.

Según el autor que lo prologa «el manuscrito de Diago no forma un todo orgánico, son notas diversas, sin conexión alguna» (121). Se encuentra dividido en diversos epígrafes que pueden estar dedicados a una localidad: Gandía, Xátiva...; familia: Belvis, Çanoguera...; o ser extracto de diversos manuscritos. Esta obra publicada a principios del siglo $X X$, por su fecha de edición y escasa relevancia de las noticias aportadas no la hemos tenido en cuenta.

\subsection{Estructura de la Generalidad a través de los cronistas}

Las obras de los cronistas valencianos mencionados no son útiles en su mayoría a nuestro estudio. Unas veces porque el período cronológico que comprende la crónica es corto y no abarca el tiempo en que surge y se desarrolla la institución que nos ocupa: Beuter, Diago. Otras porque precisamente el volumen que contendria los datos interesantes para nuestro tema se ha perdido: Viciana.

Sólo un cronista adquiere un relieve singular, según se desprende del apartado 2.3.

La importancia de la obra de Escolano, para nuestro tema, radica en el doble planteamiento que, sin duda, actúa de forma complementaria: la institución sigue su normal desarrollo en esa época, la crónica está dedicada a los diputados como representantes de los tres estamentos.

Según este autor la Diputación es un gobierno de los tres estamentos cuyos fines son la conservación de los fueros y defensa del reino.

Al frente de la institución están los diputados cuya misión consiste en la administración de las rentas y tributos. Su origen lo retrotrae al siglo XIV. Fecha clave en la organización administrativa del organismo sería 1419, aunque menciona ya el nombre de los diputados en 1406. Para el cronista, 1419, es la fecha en que se establece definitivamente

(118) GARGANTA J. M." Op. Cit., págs. X-XI.

(119) CASTAN̄EDA Y ALCOVER, V. Op. Cit., pág. 42.

(120) Apuntamientos para continuar los anales del reyno de Valencia desde el rey Pedro III hasta Felipe II. Valencia 1936-42.

(121) GARGANTA J. M.a Op. Cit., pág. XXVII. 
el número de diputados, dos por brazo, y se nombran el resto de oficiales ordinarios contadores, administradores y clavarios, su período de ejercicio queda establecido en tres años; el abogado, síndico y escribano son perpetuos.

La jurisdicción de los diputados es total en lo concerniente al organismo que regentan y asuntos con él relacionados, según fuero de las Cortes de 1510.

La financiación ordinaria de sus objetivos se realizará a través de ciertos impuestos. Estos reciben el nombre de General porque no reconocen ninguna exención personal, sólo los productos dedicados al culto divino. Estos tributos introducidos en el siglo XIV, en fecha que no precisa, son llamados General viejo y se confirmarian en 1403. El General nuevo, introducido en 1604 , le resulta más familiar y especifica las materias sobre las que incide: naipes, sombreros, sal y nieve. La cifra total que alcanzan ambos derechos, según él, asciende a cien mil ducados.

Da también noticia del edificio que alberga el organismo, iniciado en 1419 es, según Escolano, "una de las cosas magestuosas desta ciudad".

Así pues, y según lo expuesto, las noticias aportadas por Escolano, cuya matización no corresponde hacer aquí, serán las que nos ofrezcan la visión más clara de la Generalidad mientras el organismo se encuentra todavía en funcionamiento.

Podemos concluir pues que de todos los trabajos mencionados los más fértiles para nuestro estudio han sido el Libre de Memories y la Década de Escolano. Ambos autores son contemporáneos a la institución que nos ocupa, ello les sitúa en una proximidad envidiable para exponer la estructura administrativa y financiera del organismo durante la época moderna. Esa misma proximidad, sin duda, dificulta tanto el estudio de sus orígenes como el significado de la institución en el contexto sociopolítico valenciano hasta 1707 .

El Libre de Memories no trata directamente de la Generalidad, sus datos se entresacan de noticias relacionadas de alguna forma con la institución. Escolano, sin embargo, inserta la descripción del organismo dentro de un plan previo, por ello la exposición es más coherente y ordenada, incluyendo sus fines y objetivos. Su calificación, como escudo y protección de todo el reino, responde a un sentimiento que perviviendo hasta nuestros dias ha hecho posible el resurgimiento de la institución. 